\title{
Sociology of Development and Education: An Epistemic Continental Approach
}

\author{
Olayinka Akanle \\ ORCID iD: https://orcid.org/0000-0002-4707-4491
}

Gbenga Adejare

ORCID iD: https://orcid.org/0000-0003-1893-6328

\begin{abstract}
This article engages how Sociology of Development, as a unit of Sociology, interfaces with Education within broader ontological and epistemic constructs to agitate increased attempts for an Africanist approach as an alternative perspective to examining disciplinary interlinkages relative to Education. While there are divergent approaches and theories that culminated in Sociology of Development, a careful interrogation of how such approaches and theories are suited within the spaces of histories, epistemologies, cultures and ethnographies of African landscape for effective education is central to this article. This is not only because this subfield of Sociology in Africa is budding and relevant to general knowledge production, but also because it is consequential for the relevance of the discipline and its branches, including Sociology of Development and Clinical Sociology, on the continent of Africa and in global scholarship.
\end{abstract}

Keywords: Sociology, Sociology of Development, Epistemology of Knowledge and Education, Africa.

\section{Introduction}

Africa occupies a central position in understanding and discussing flipsides of development (Gore 2000), underdevelopment (Rodney 2005), quasi/ pseudo- 
development (Akanle \& Adejare 2019), non-development and trajectories of education. While this article focuses on Sociology of Development, it is impossible to pursue this focus without recourse to its broader knowledge systems in contextual terms. This context is possible to be continental, as is the case in this article. It is possible to sociologically, re/narrate historical, experiential and existential trajectories of development in Africa, excite reflexive studies that will have direct bearing on the culture and lived experiences of the people of Africa, and de/reconstruct the ambiguities that linear theorists have associated with the concept of development and knowledge production in Africa (Akanle \& Okewumi 2019). The bases usually advanced for studies on Africa include poverty, wars, conflicts, terrorism, illiteracy and persistent underdevelopment. It is thus important to transcend these bases to enhance knowledge on Africa through Sociology of Development for robust African epistemology.

Even though Sociology of Development is at the level of intellectual and academic impasse globally as a result of epistemic contests and disciplinary saturation (Kiely 2013), the discipline remains contextually relevant in Africa as Africa continues to struggle with aggravated underdevelopment. The epistemic impasse of previous paradigms was largely due to the incapacity of scholars within the discipline to fashion a collective disciplinary approach to make the discipline more applicable and adaptable across contexts in manners decolonized from European origin and epistemology of Sociology (Phatlane 2016). Social thoughts in this case include local and contextual proverbs, idioms, concepts, wise sayings, argots (like Ubuntu and Omoluabi) drawings, songs and dance, for instance.

A major consideration in managing academic impasse is the need to better retool the discipline to local contextual orientations especially in Africa where the discipline is being taught after wholesale adoption from Europe (Lutcovich 1996). Even though Sociology of Development has gone through a number of changes since its emergence and introduction to mainstream Sociology, the introduction of local contents and regional inputs as well as orientations have remained poorly inculcated in Africa, as most transformations in the discipline have been mostly in Asia, America and Europe (Omobowale \& Akanle 2017; Akiwowo 1974; Akiwowo 1980; Akiwowo 1986a: Akiwowo 1986b: Alatas 2003; Alatas 2008; Alatas 1969; Alatas 1972; Alatas 1974; Sitas 2006; Sitas 2011; Sztompka 2011). These somewhat account for why the discipline has little or no African cases and inputs, as 


\section{Olayinka Akanle \& Gbenga Adejare}

noticeable in Sociology of Development and Clinical Sociology, for example. The relevance of Sociology, including Sociology of Development and Clinical Sociology, will depend on how much and how well contextual knowledge systems are factored into the discipline. The knowledge infrastructure and architecture to drive growth and development on the continent however remain challenging; thus, the need for epistemic engagements at the levels of discipline and context.

While there have been epistemic interventions in Sociology across the world, there has been no appreciable success in this regard on the African continent (Akiwowo 1974; Akiwowo 1980; Alatas 2008; Sitas 2011; Sztompka 2011; Akanle 2012) thereby necessitating further attempts and interventions. Given the need for a more contextual understanding of social realities and postmodern ways of knowing, there is a need for Sociology of Development, including Clinical Sociology, to go beyond grand narratives and established ways of knowing which originated from the beginning. There is a need to understand the conventional paradigms better and appreciate their weaknesses, as well as note that knowledge is dynamic, and Africa must understand conventional knowledge, appreciating the prisms of contextualisation of Africa.

While the conventional order of knowledge may still be relevant, there is a need to constantly appreciate continue engagement with the African ways of knowing, which is building African experiences and epistemologies into writings of Sociology of Development and Clinical Sociology. Knowledge is dynamic and a common dynamism within the current knowledge systems of Sociology of Development is the need to drive more towards African knowledge systems. It is at that point that the discipline and the practitioners can be better appreciated and understood as well as being relevant in Africa. It is only after this that students, academics, scholars and policymakers will find the discipline applicable. This is very important, because Sociology of Development's approach to knowing only and mostly through the way of the North has left the discipline little understood, poorly subscribed to and weakly appreciated in Africa. This article is therefore interested in introducing African contexts into major issues/elements of Sociology of Development as case studies for Clinical Sociology to broaden its scope, understanding and applicability. This is particularly so as development has an applied dimension and there is the need to appreciate the context of the application for relevance. There is a need to decolonize and Africanize Sociology and its units, Sociology of Deve- 
lopment and Clinical Sociology, because development itself is value- laden and the contexts of value are important for the application of knowledge to work. People often perceive development as positive, but this depends on who defines the development and for whose interests (Akanle \& Adejare 2019).

This article is largely theoretically based on a systematic review of literature. It demonstrates the gaps in African perspective on Sociology particularly Sociology of Development and Clinical Sociology. The article noted that the decolonization of contents of Sociology of Development, Clinical Sociology and Sociology generally is very weak and nascent. There are no coordinated efforts on the African continent to decolonize contents in real terms. South Africa is the only country in Sub-Saharan Africa, particularly, struggling to decolonize contents. However, even in South Africa, decolonial content is still difficult to include in actual curricula, given the global homogenization of Sociology and its units/sub-fields.

\section{Development in Context: Towards Adaptable and Sustainable Knowledge Production}

Development is commonly utilized and weaponized. On the African continent, development is nearly now seen as elusive and as a theoretical issue that is near impossible (Akanle \& Shittu 2019). Development is also usually seen as only possible when western societies are involved. It is also used and considered an elite issue only meant for real in developed countries. It is also theoretical and policy entity to subjectively categorize and/or recategorize the world into uneven yet interrelated units - such that economic growth is inexpediently interchanged with development. There is no consensus about the definition of development, because different perspectives exist on its subject matter. It is important to interrogate the difference between development and growth. Growth suggests a unilateral improvement that can be measured in terms of statistics - size, weight and volume. An example of growth is a gradual increase in income of a country or a household. Development, on the other hand, refers to holistic improvement in various part of a system (Kaplan 2002). Development is as a result of coordinated series of growth. An example of development is when there is intersectoral improvement that translates into the improvement of lives and property of the people in an economic system (Akanle \& Adejare 2019; Akanle \& Shittu 2019). While growth can occur without development, development is impossible without growth. 
Development is about human life. It entails sustainable improvement in various institutions for the purpose of making life meaningful to people in the society. Indices of quality development in any country include, but are not limited to, an adequate supply of social amenities, and a high standard of living, as well as improved standard of education. There are also gender, economic, geographic, political, demographic and cultural dimensions to the discourse of development. At the macro-level, development addresses issues of migration, economic growth, poverty level and national income. At micro-level; development is concerned with individual access to justice, education and other lifeenhancing opportunities. Development, is concerned with raising standard of living, the improvement of people's self esteem within enabling institutions and increasing freedom of choice in society. Development can also be seen as a progressive increase in the capacity of a community or society to satisfy essential needs for the livelihood of its members (Akanle \& Adesina 2018).

Development is positive structural changes in the core components of the society like health, ecology, living standard, family life, level of literacy and other things considered indicators of progress in a given society. It is the change that touches the lives of the people as individuals and groups must feel its consequences in all social institutions of society. It means observable desired change and movement in the culture and quality of life in extensive and deeply penetrating manners (Abdi 2010). That is a desirable change in law, family, security, economy, health, education, media, technology and life expectancy with positive implications on the lifves of the people. Development is practical and an impactful and effective issue. It is not a mere academic, theoretical and policy issue. It is very practical and touches on people's existences. Development borders on people's total being - social, economic, political, medical, familial, religious and psychological. Development affects people's health, psychology and mental health and Clinical Sociology becomes very important and comes to focus on this level. Development affects health in definitive terms and manners. If development in African context is very problematic, it is therefore only expected that the totality of being on the continent will be uniquely challenging and Clinical Sociology is much needed and must factor contextual development scenarios and realities of Africa in its interventions.

According to Rodney (2005), development in human society is a many-sided process. Development is also a multifactorial issue that can be best driven and understood in context. At the level of individual, development im- 
plies increased skill and capacity, greater freedom, creativity, self-discipline, responsibility and material wellbeing. For Rodney (2005), development connotes enhanced and increased skills and capacity, greater freedom, creativity, self-discipline, responsibility and material wellbeing of people in societies. Development is a concept that is contested both theoretically and politically, and is inherently both complex and ambiguous. Some have presented a limited meaning of the practice of development agencies, especially in aiming at reducing poverty and the Millennium Development Goals (Saith 2007). The vision of the liberation of people and peoples, which animated development practice in the 1950s and 1960s, has thus been replaced by a vision of the liberalisation of economies (Saith 2007; Rodney 2005). The goal of structural transformation has been replaced with the goal of spatial integration. The dynamics of long-term transformations of economies and societies continually slip from view and attention was placed on short-term growth and re-establishing financial balances. The shift to ahistorical performance assessment can be interpreted as a form of the post-modernization of development policy analysis (Gore 2000).

\section{Sociology of Development: Theoretical and Contextual Diagnosis and Prognosis of Africa's Development Question}

Sometimes referred to as Development Sociology, Sociology of Development is a sub-discipline or subfield of sociology. It is a specialization area studied/taught and practised at higher institutions of learning. Unlike Development Economics, social intercourses reflecting values, traditions, norms and beliefs of a people and how they are transferred from one generation to another are of greater interest to development sociologists, rather than statistical growth of economy of industrialisation level (Akanle \& Adejare 2019). The rigour of the discipline lies in its appeal to epistemology, ontology, hermeneutics, historiography and sociological imagination to enquire the trajectories of tangible and intangible aspects of development of a people (Saith 2007). Hence, Sociology of Development is more inclined towards interpretivism rather than positivism.

Given this line of explanation, it can be argued that Sociology of Development is a branch of science - since science is about knowledge - that concerns itself with a holistic enquiry into the causes and courses of societal advancement(s). Beyond this knowing is the importance of application: how is 
this science or knowledge applied and contextualized? This question has significance in interrogating the devolution of concept of development globally through labelling some parts developed and others either developing or undeveloped. To attempt the epistemological explanation of how to apply the scientific knowledge advanced by the development sociologist, it is pertinent to first examine explanatory frameworks in the field.

The concept of development is problematic in Africa, both in theory and in practice, due to contorted and waffled interpretations of social realities in Africa by many Western development scholars (Emeh 2013). It appears rather more difficult to isolate Africa to explain development without reference to the past, present and potential influence of global interactions on the continent. It thus means that it is plausible to explore endogenous and exogenous factors responsible for social, political and geo-economic landscapes of the continent. One way to weave these would be to examine the impact of globalisation in African development trajectories. In contemporary terms, issues relating to terrorism, epidemic outbreak, economic recession, finance, migration, population, and urbanisation, among others, assume global dimension. Consequent upon this, the economic, social and political institutions of the various nations are systematically enmeshed within the web of globalisation, such that global best practices now serve as the yardstick for measuring behaviour and performances at the local level - this is fondly referred to as glocalisation (Ritzer \& Stepnisky 2014).

The impact of globalisation on the development of different countries of the world, with special regard for countries with social and economic crises, continues to engender lots of ambivalences. In the view of Afrocentric scholars, the structure of the post-modern world is essentially favourable to the more developed countries of the global West ${ }^{1}$ (Igun 2007). The argument is that due to persistent issues of economic redundancy, political instability, a low level of literacy, technological backwardness and other factors whose causes are not ahistorical, the less developed countries of the Third, or Developing World ${ }^{2}$ have not been properly integrated into the global system. This, by implication, makes the latter subservient to the former in the global system. Development within this framework is a function of the interactions taking

\footnotetext{
${ }^{1}$ These are countries like Canada, United States of America, United Kingdom and most countries in Europe.

${ }^{2}$ These are mostly countries in Africa, Asia, Caribbean and Latin America.
} 
place within the global system

Bringing the wave of globalisation to bear within the ambit of development, the daunting challenges facing national survival and development range from cultural sustainability, strengthening local industries to compete favourably within the global space, improving the level of literacy, face-lifting technological capacities in the country as well as sustaining indigenous values, to mention but a few. This is not an easy task; yet the reality remains: globalisation has come to stay. In reality, depending on the leadership of the country, globalisation can either be a threat or a catalyst to development in Nigeria. It is going to be a threat if Nigeria continues on the part of consumerism and international subservience. Conversely, globalisation will be a blessing if the country's rich culture and resources are well galvanised to make the country relevant in global space. Akanle and Abayomi (2013) corroborated this view in their argument for and against globalisation.

Current intellectual advances in Development Sociology reflect some deficiencies in the appreciation of Africa-oriented schools of thought. Much of what is thought and how it is taught in terms of content and pedagogy are drawn from Europe and America. While this is understandable to the extent that the origin of the discipline is from Europe and America, current realities suggest the need for more inclusive pedagogy and content in the discipline. This is because completely foreign content, methodology and syllabi cannot sufficiently understand historical and current realities of all societies, especially in and of Africa. African-centred theoretical and conceptual frameworks are therefore necessary at this level. This will enhance the understanding of the discipline among practitioners and scholars and will improve its relevance on the continent. It must however be noted that the near exclusion of African pedagogy and content from Development Sociology is not peculiar. It is common to sociology as a whole and social sciences and beyond in general.

This is why there has been recurrent call for decolonisation of the social sciences in Africa, as the area of knowledge continues to regurgitate colonial and post-colonial contents and pedagogy (Akiwowo 1974). Rather than this decolonisation of knowledge in the social sciences, however, there appears to be continued globalisation and homogenisation of knowledge in terms of content and pedagogy. A common reason for this is the belief that the more global, the more professionally acceptable. There is also the belief that not much can come from Africa in terms of relevant scientific knowledge. Foreign concepts, methodology and pedagogy therefore continue to be adopted 
in analysing African development issues. Little wonder then that African development quagmires continue to be poorly understood and underdevelopment continue to exacerbate. For instance, Meredith (2011), from a disjointed historical parlance, portrayed Africa as drifting further away from development. because many countries in the continent, out of desperation, borrow heavily instead of adopting austere policy measures that would lead to currency devaluation. A similar trend is replicated in the writing of Kararach (2014), who blamed the inability of most countries in Africa to meet the set MDGs on inherent climatic and attrition in capacity of government in the continent to manage the affairs of their people. The paradox here is that there seems to be a seesaw movement of African development simply because of the pool of nonAfrican ideologies about the concept of development pathway.

Development Sociology largely needs Africa-centred approaches and syllabi to be effective and relevant on the continent. This Development Sociology being proposed and agitated for will adopt and use African-centred epistemology, ontology, methodology, theory and pedagogy that can capture African realities. This is not a Development Sociology that will be totally severed from the global discipline but one that is glocal - globally relevant, yet locally useful and understood. This is a needed advancement in Development Sociology. This approach will better study and deploy African culture and worldviews scientifically in understanding local and global development issues. This sociology will be hybridised, but never undermine the local contents and approaches, unlike what is currently obtainable. African culture and worldviews in hybridised methodology, ontology, theory and epistemology are particularly important. Cultural variations of Africa must be well understood and factored into the Development Sociology's analytical equation to be more effective and relevant. Since these cultural variations are pervasive and strong throughout Africa and they significantly impact people's actions and inactions, and these largely determine development outcomes, they must then be included in the intellectual processes. It must be emphasised that until these varied and myriad African sociocultural and institutional realities are taken on board, development theories and methodologies, including other content, can never engage in any meaningful and productive analysis of African societies.

Africans have their unique ways of living and interpreting realities and these are codified in the culture, social relations, norms, mores, traditions and institutions. These interpretation processes and drivers must be well appre- 
ciated and accepted disciplinarily. According to Carroll (2014), the patterns for interpreting reality or deep structure of culture gives and provides a more profound understanding of culture and it is the manner in which we engage social and lived phenomena at a conceptual level. This is also true scientifically in defining concepts, choosing theories, deploying methodologies, surveying issues and giving recommendations. Poor appreciation of the contextual interpretations of realities in and of Africa remains one of the major problems of the social sciences and Development Sociology in Africa and that is why most of the existing studies, findings, theories, concepts and methodologies remain vacuous and invalid for the continent. This situation has had huge implications for various policy regimes in Africa, especially from the 1960s. There is growing consensus among Afrocentric development scholars that SAP, among other models of development introduced to Africa, has done a lot of acute damage to the development of Africa (Idyoroguh 2002). The Bretton Woods' SAP saw to the penalisation and impoverishing of farmers and rural dwellers, an increase in the level of unemployment, the devaluation of currency, insecurity and demographic challenges.

So, in engaging philosophical assumptions, contents and methodologies in Development Sociology, African cosmology, religions, ontology, epistemology, traditions, social thoughts, axiology, values and cosmogony are equally important. This is only when African worldviews, orientations, actions and inactions can be sustainably understood and deployed for real development. Most of current Development Sociology's contents are offshoots and the direct imposition of western epistemology, ontology and cosmology. How then can they be totally useful in understanding, explaining and solving African development problems - a totally different social system? (See also Idyoroguh 2002 and Carroll, 2014). From a solution and African perspective, Development Sociology in and for Africa must be environmentally and historically relevant with place-based alternative narratives and significantly decolonised processes going forward. Until this is done, the discipline/subdiscipline may be no more than a mere Western rehash.

Current syllabus and pedagogy are embedded with perspectives that contradict and struggle with African ways of life and epistemologies. This conflict is fundamental, and many African scholars continually struggle with conflict of interest. Current perspectives, theories, contents and methodologies ignore important African knowledge systems and socio-economic power relations and desires. While Africa, for example, is not originally, historically 
and existentially capitalistic, current Development Sociology, like other social sciences, are heavily designed and driven by capitalism and its practicophilosophical tendencies. The African knowledge marketplace thus remains only metropole/ satellite/ periphery merely suitable as testing ground for Western development theories, even when the theories continue to fail and African scholars who are caught in the morass struggle to explain these redundant theories and approaches to unsuspecting scholars.

Often, even when African scholars know these theories are not functional in the face of African socio-economic and historical realities, it is very difficult and nearly impossible to supply African alternatives (Bhambra 2013). This is for two main reasons. First, African scholars themselves do not unite on the issue of the need for more African-centred social sciences. Many believe their relevance lies in functioning within the global framework and by teaching global syllabi and western contents the western way. There are therefore conflicting vested interests of African scholars for various reasons. Secondly, and the most critical, Northern/Western intellectual hegemonies hold sway and the process of disciplinary alternatives from the South (including Africa) is difficult and nearly impossible, as already demonstrated in the Akiwowo's case. Even against these two critical challenges, Africa alternatives may be on the way, but African scholars must first agree on the need for this and forge a common front to push this to global scholarship and audience. They must unite, remain resolute, discuss it, write about it and push it while forging alliances with like-minded critical scholars from the west and other continents. African scholars must however first generally and commonly agree there is need for more Afrocentric alternatives. This initial agreement is crucial, because a house divided against itself cannot stand. It is only then when a more functional and relevant African-centred Development Sociology can be possible.

\section{Theories of Development: Explaining Development in Sociology}

There are a few theories in Sociology of Development. The primary objective of these theories is to explain development as an outcome and process. These theories are both epistemological and pedagogical interventions in Sociology as scholars and the discipline grapples with development as an emergent and age-old challenge that will never go away, yet in need of continuous engagements. 


\section{Modernization Theory}

A major theoretical tradition in Sociology of Development is the Modernization theory. Modernization Theory evolved as an offshoot of the earlier unilinear evolutionary explanation of society (as in the society changing from one level of civilisation to another), especially as expressed in the works of forerunners of sociology like Auguste Comte, Herbert Spencer, and later in the works of Walter W. Rostow, Ferdinand Tonnies and Talcolt Parsons (Ritzer \& Stepnisky 2014; Idyorough 2002; Akanle \& Adejare, 2019). Entrenched in the unilinear social evolution (social Darwinism) is the belief that all societies have to follow a specific path to experience transformation from simple to complex or from traditional to modern or from a pre-industrial to an industrial society.

According to Talcolt Parsons, all societies should, or better still, must possess the functional prerequisites of AGIL (Adaptation, Goal attainment, integration, and Latency) to move through the stages of development (Idyorough 2002). Adaptation refers to the ability of the social system to survive and exercise supremacy over all forms of hardships so as to be able to provide for the needs of the people. Clothing, shelter, education, and all forms of human needs are constructed and provided for by the social institutions upon whom certain demands have been placed by the social system. Goal attainment refers to targets and priorities that are set in the social system, such that all institutions of the society work in a coordinated manner - the political institution is responsible for setting the goals. Integration is deemed a prerequisite that brings about asymmetry in the social system. The institution of law is charged with this function within the Parsonian conception: it specifies rules and regulations that ensure proper behaviour and actions of people in a particular society. The last prerequisite is latency, which in turn connotes patterns of norms and values that are sustained or maintained. The institutions of religion, family and education, in socialisation processes, are at the heart of this function. Parsons further identifies certain 'universals' of evolution, as

(i) Communication through the use of language;

(ii) Religion;

(iii) Kinship; and

(iv) Technology.

Accordingly, these universals essentially serve as catalysts for the trans-forma- 
tion or evolution of societies from a simple to a complex society. A simple society, within the context of this explanation, is characterised by affectivity, diffuseness, collectivism, particularism and ascription. On the other hand, a complex (supposedly modern) society is believed to possess futures such as affective neutrality, specificity, individualism, universalism, and achievement, all of which sharply contrast with those of a simple pre-industrial society.

Several criticisms have been levelled against the modernisation theory since its inception in the 1950s. This theory has been seen as being largely inadequate in explaining the social changes that occurred in the $19^{\text {th }}$ and $20^{\text {th }}$ centuries. For instance, the theory has failed to encapsulate the social disorder and all forms of agitations for human rights replete in the period. The theory has also been termed 'ethnocentric' and 'Eurocentric' (Emeh 2013; Abdi 2010; Rodney 2005), as it favoured the Western world, ignoring the early development in African countries like Egypt, the cradle of civilisation, and Ethiopia, among others. Perhaps, the most unpardonable negligence of this theory and its proponents is the inability to capture the role of slavery and colonialism that relegated the now 'undeveloped' parts of the world to the ground. In fact, the dependency theory derived from the pitfalls and deficiencies of modernisation theory.

\section{Dependency Theory}

Another popular theory of development is the dependency theory. Borne from the need to explain development processes from another standpoint different from that of modernisation, dependency theory is hinged upon Marxism. It adopts historiography to interpret hitherto existing capitalist societies. Paul Baran has been credited to be the first proponent of dependency theory (Idyorough 2002). Other contributors include Andre Gunder Frank, Theotonio Dos Santos and Walter Rodney, among others. The premise of the theory is that it is largely inadequate to depict different countries as taking the same path of development. Modernisation theory is accused of being ahistorical within this theoretical framework. The theory tilts towards exonerating Third World countries from an ascribed original state of 'no development' - underdevelopment being explained as caused and not an original state.

Stemming from the core idea that spurred dependency theory - setting the explanation of development and underdevelopment straight - it can be deduced that both development (of the Western world) and the under- 
development of the Third World may not be fully comprehended without taking into consideration the history of capitalism and unequal relations that have hitherto existed between the two polar regions. It is from this angle that an attempt was made by Latin America to strengthen endogenous economic strides and discourage overreliance on foreign economic which has the potential of further impoverishing the poor nations of the world, hence the formation of Economic Commission of Latin America (ECLA).

\section{World Systems Theory}

The World System Theory (WST) popularised by Immanuel Wallestein is another popular theory of development. In his book, The Modern World System, Wallerstein introduced the concepts of core, periphery and semiperiphery. WST theory explains that the history of the world has been that of strong empires where less powerful empires are subjugated. Within this context, the core comprises of the economically powerful countries of the world, the semi-periphery are made up of the emerging nations, while the periphery are the poor countries of the Third World. The tripartite system is believed to be laced with unequal relations, subjugation and consequential for development or underdevelopment, as the case may be. In spite of the strength of the argument put forth by the dependency and world system theorists, it has been argued that both theories are better seen as mere flipsides. According to Akanle (2012), both modernisation and dependency theories are 'grand and macro-theories with difficulty of proof and micro-relevance'. Dependency theory has also been seen as guilty of the same accusation levelled against the modernisation theorists - grouping the world into those that are developed and those that are not; ignoring the fact that culture and time are special indicators of the level of development at a point in time. Thus, ambivalencies exist as to the completeness of the two dominant theories of development. Although there are other brands of theories that have been put forward to explain development, like the Latin American structuralist school spearheaded by Fernando Henrique Cardoso, a former president of Brazil, the neoliberal school and the post-modernist perspective, it seems most of the emerging theories do differ from the initial concerns raised by their predecessors.

The main task of neo-modernisation theorists was to see to transforming the ideas of modernisation theorist to suit social dynamics. As explained by Knobl (2003), further embrace of democratic regimes by about 
121 states since 1987/8 led to the evolution of neo-modernism (also known as modernism II). According to this school of thought,

(i) modernisation results from individual and collective actions, and not from development of systems;

(ii) modernisation seeks new ways to achieve their goals and fulfil their values, accomplishment of which is dependent on resources available;

(iii) modernisation occurs as a result of competition between modernisers, conservatives and bystanders and not a consensual process;

(iv) science is a major driving force, but religion and tradition must not be undermined;

(v) welfare development of the entire population is the main criterion of modernisation;

(vi) centres of modernisation are not necessarily static; they may change and/or move; and

(vii) modernisation has cycles and regressive crises and not continuouslinear (Knobl 2003).

It is important to note that, although neo-modernisation theory added flesh to decaying modernisation theory after it had seriously been attacked by several critics, especially the dependency and world system theorists; yet the theory has been challenged for its failure to account for the opposition it attracted from non-western states which has been seen as a "clash of civilisation', better still, 'West against the rest' (Knobl 2003: 40).

Third World development discourse is another important dimension for interrogating the larger context of international development (Kararach 2014). Patterned on the Third Estate of the 1789 French Revolution, Alfred Sauvy purportedly coined the term the 'Third World' in 1952 (Emeh 2013; Akanle 2012). It was first introduced to describe independent countries outside the two major contending blocs during the Second World War. Subsequently the term have been used to categorise the developing states of Latin America, Southern part of Asia and Africa. The nature of interactions between the core of West and the periphery has largely been blamed by dependency scholars for the perceived low level of development in the Third World countries. Geographically, most countries of the Western region in the world map belong 
to the category called Third World (as against cosmopolitan Northern countries) (Olutayo \& Omobowale 2007). Development indices like per capital income, mortality rates, national income, level of industrialization and poverty level, among others, have been used as parameters for categorising the world into two broad dichotomies of developed and developing by modernist scholars.

According to Olufemi Adelakun:

Development here is conceived as societal mobility from traditional state to social equilibrium maintained by the operation of functional imperatives of AGIL, mediated through a set of pattern variables that are determined by the social structure (Adelakun 2008: 78).

A picture painted by Olutayo (2002) shows two thirds of the world population are from the impoverished third world countries. He was also explicit about the existing unequal relationships between the agrarian third world and the industrialised west. Similarly, the Human Development Index (HDI), measured in terms of life expectancy, educational attainment and adjusted real income given by United Nations Development Programme (UNDP), also depicts vast decimation of most Third World countries (Akanle \& Adejare, 2019). Certain socio-demographic characteristics, to take a very relevant example, of developing countries, would include comparatively high growth rates, low life expectancy, and a high proportion of children in the population. Industrialised countries tend to have low population growth rates, relatively high life expectancy, and a high proportion of older people in the population. Mortality rates tend to be high in developing countries, and the combination of factors causing deaths is very different to that in industrialised countries.

As relevant as these theoretical orientations are in understanding development, there is however need for alternative African Sociology and Sociology of Development. This is only when development and sustainable development can be achieved on the continent. Imported and foisted epistemologies that are poorly adapted can never explain African realities sufficiently. This is not limited to Sociology of Development but other areas, including Clinical Sociology. This alternative African Sociology of Development will provide alternative or/and complementary viewpoints and inclusive knowledge. Alternative African Sociology should be home-grown, but must also be globally competitive and adapted. This is not African Studies or Area 
Studies. It is a discipline that is primarily concerned with understanding African social relations, values, norms, culture, psychic, social processes and social institutions and how they impact and affect development.

The discipline will not rely on the wholesale utilization and study of Africa through foreign epistemologies and curricula. This alternative viewpoint will, however, not be limited to Sociology of Development, because this is also important in Clinical and Medical Sociology that relies nearly entirely on theories, practice and frameworks from the West. A major reason it has been difficult for Sociology to explain development in Africa is the lack of real and extensive Afrocentric approaches in Sociology (Rodney 2005; Akanle \& Okewumi 2019; Akanle \& Adejare 2019). However, a more formidable challenge to African alternative approaches in Sociology is global acceptance of local epistemic interventions. In a discipline with epistemic hegemony and certification in the North, how will an alternative from the South be certified and accepted as an adopted and acceptable perspective bearing in mind there is globalization of knowledge and certification? (Welz 2009; Udefi 2014). Concerted attempts must be made at indigenizing Sociology including Sociology of Development and Clinical Sociology. Cases of Asia, particularly India, are very relevant here (Welz 2009). Even though Indian Sociology is now more than 100 years old, aggregated efforts and investments were made early in indigenization and these have yielded some positive results. Alternative approaches are more visible in India than in Africa. Even though Indian Sociology is still at the global margin, it is becoming more forceful and being reckoned with and that is somewhat progress.

Africa should follow suit in a determined manner.

Most African countries do not make sufficient efforts in respect of African alternative perspectives in Sociology, Sociology of Development, Sociological Theory and Clinical Sociology. The only country at the forefront of Africanization of Sociology in Africa is South Africa, and even this can be more coordinated and pursued. African culture, experience, values, social thoughts, methodologies, approaches and indigenous life courses should be married with global frameworks to provide unique African perspectives that will explain and address African development and health issues. Of importance is that the time for more determined, concerted and ambitious African approaches and alternatives is now, and all scholars must more be determined and be involved if positive and useful problem solving knowledge is to be achieved on the continent. 


\section{Conclusion}

The article has shown that while development is an expansive and often conflated concept, its ramifications are very useful in forging scholarship in Sociology - Sociology of Development and Clinical Sociology - and interrogating, explicating, narrating and theorising Africa. Dominant western theories and epistemic hegemony have succeeded not only in dominating the global sociological knowledge space, but also in under-narrating and epistemologically denigrating the development, cultural and historical trajectories of African knowledge systems. This intellectually and pedagogically undervalues and underutilizes the potential of African knowledge systems and capabilities. While attempts have been made to unravel how Africa has been intellectually enmeshed in unequal global interactions which, of course, has greatly impacted on economies, knowledge production, cultures, polities and development (Omobowale \& Akanle 2017), more needs to be done in marshalling Africa's alternative viewpoints.

It is noteworthy that theories of the sociology of development originating from the West have harmed the understanding and appreciation of the African context and ontology. Unfortunately, African explanations have not made it into mainstream curricula. There is a major challenge to institutionalizing Sociology, Sociology of Development and Clinical Sociology. The journey to including and teaching 'African Sociology of Development' appear distant while Northern intellectual hegemony holds sway (Connell 2007; Connell 2013) and African higher education ministries do very little to decolonize and institutionalize African Sociology. Even when there is increasing Africanism on the African continent and this is pushed aggressively academically, theoretically and empirically, it is noteworthy that this is mostly only the case in South Africa. Africanism as a theoretical, methodological and empirical epistemic intervention is mostly a South African project, as the same determination to decolonize and Africanize Sociology, including Sociology of Development and Clinical Sociology has not penetrated the continent in real terms (Omobowale \& Akanle 2017; Alatas 2008; Alatas 2003; Akiwowo 1986a; Akiwowo 1986b; Alatas 1972; Alatas 1969). Even in South Africa, this epistemic effort is yet to be very established and it has not been seriously included in curricula. In the absence of consensus, assumptions, claims and campaigns do not qualify as knowledge.

In Africa, South Africa has been at the forefront of the decoloniza- 
tion of knowledge, especially in Sociology. More efforts, however, are needed for aggravated impacts and more continent-wide epistemic intervention and alternatives. Moreover, the time is now if scholarship and practices will serve any useful purpose for development, scholarship and practices on the continent and beyond. Interestingly, until the varied and myriad African sociocultural and institutional realities are taken on board, through Africanism and decolonial contents in Sociology, Sociology of Development and Clinical Sociology, development theories and methodologies, including other contents, can never engage in any meaningful and productive analysis of African societies. This article has given insights into African epistemic intervention in a North-dominated intellectually hegemonic space. While it may not be easy to provide globally acceptable African alternative epistemologies for knowledge production and development, given the current heavily tilted intellectual context, the journey on the continent must start now and it must be inclusive. The journey must, however, not only carry along scholars/ sociologists on the continent, but also those outside the continent and those not even from the continent.

\section{References}

Abdi, A.A. 2010. Globalisation, Culture and Development: Perspectives on Africa. Journal of Alternative Perspectives in Social Science 2,1: 1 - 26. Adelakun, A.O. 2008. Theoretical Approaches to Development and Underdevelopment. Nigeria: University of Jos Press.

Akanle, O. \& Abayomi, A.A. 2013. Sociology of Development. In Aborisade, R., A.O. Omobowale \& O. Akanle (eds.): Essentials of Sociology. Nigeria: Ibadan University Press.

Akanle, O. \& Adejare, G.S. 2019. Foundation of Development Sociology. In Abdullahi, A.A. \& E.M. Ajala (eds.): Contemporary Issues in Sociology and Social Work. Ibadan: College Press, Lead City University.

Akanle, O. \& J.O. Adesina 2018. Introduction: The Development of Africa: Issues, Diagnoses and Prognoses. In Akanle, O. \& J.O. Adesina (eds.): The Development of Africa: Issues, Diagnoses and Prognoses. Berlin: Springer. https://doi.org/10.1007/978-3-319-66242-8_1

Akanle, O. \& O.E. Okewumi. 2019. Contemporary Sociological Theories: An Africanist View. In Abdullahi, A.A. \& E.M. Ajala (eds.): Contemporary 
Issues in Sociology and Social Work. Ibadan: College Press, Lead City University.

Akanle, O. \& O. Shittu 2019. When Development Appears Impossible: The Unending Development Question of Nigeria. 42 $2^{\text {nd }}$ AFSAAP Annual Conference. 26 - 27 November 2019. Africa's Diversity and Development. University of Otago, Dunedin, New Zealand.

Akanle, O. 2012. Introduction to Development Studies. In Ogundiya, I.S. \& J. Amzat (eds.): The Basics of Social Sciences. Nigeria: Usman Danfodio University.

Akiwowo A. 1974. Presidential Address: Association for What? Nigerian Journal of Sociology and Anthropology 1,1: 3 - 6 .

Akiwowo A. 1980. Ajobi and Ajogbe: Variations on the Theme of Sociation. Ife: University of Ife Press.

Akiwowo A. 1986a. Asuwada-Eniyan. Ife: Annals of the Institute of Cultural Studies 1: $113-123$.

Akiwowo A. 1986b. Contributions to the Sociology of Knowledge from an Oral Poetry Perspective. International Sociology 1,4: 343 - 358. https://doi.org/10.1177/026858098600100401

Alatas S.F. 2003. Academic Dependency and the Global Division of Labour in the Social Sciences. Current Sociology 51,6: 599 - 613. https://doi.org/10.1177/00113921030516003

Alatas S.F. 2008. Intellectual and Structural Challenges to Academic Dependency. Amsterdam: SEPHIS.

Alatas S.H. 1969. The Captive Mind and Creative Development. In Madhava,

K.B. (ed.): International Development. New York: Oceania Publications. Alatas S.H. 1972. The Captive Mind in Development Studies. International Social Science Journal 34,1: 9 - 25.

Alatas S.H. 1974. The Captive Mind and Creative Development. International Social Science Journal 36,4: 691-699.

Connell, R. 2007. Southern Theory: The Global Dynamics of Knowledge in Social Science. Sydney, NSW, Australia: Allen \& Unwin.

Connell, R. 2013. Using Southern Theory: Decolonizing Social Thought in Theory, Research and Application. Planning Theory 13,2: 210 - 223.

https://doi.org/10.1177/1473095213499216

Emeh, I.E.J. 2013. Dependency Theory and Africa's Underdevelopment: A Paradigm Shift from Pseudo-intellectualism: the Nigerian Perspective. International Journal of African and Asian Studies 1: 117- 128. 
Gore, C. 2000. The Rise and Fall of the Washington Consensus: A Paradigm for Developing Countries. World Development 28,5: 789 - 804.

https://doi.org/10.1016/S0305-750X(99)00160-6

Idyorough, A.E. 2002. Sociological Analysis of Social Change in Contemporary Africa. Jos: Deka Publications.

Igun, U. 2007. The Challenges of Human Development for Nigeria in the $21^{\text {st }}$ Century. In Ukiwo, U. \& S. Joab-Peterside (eds.): Nigerian Society in the Twenty-First Century. Nigeria: Centre for Advanced Social Sciences.

Kaplan, H.B. 2002. Toward an Understanding of Resilience: A Critical Review of Definitions and Models. In Glantz, M.D. \& J.L. Johnson (eds.): Resilience and Development: Positive Life Adaptations. London: Kluwer Academic Publishers.

Kararach, G. 2014. Development Policy in Africa. UK: Palgrave Macmillan. https://doi.org/10.1057/9781137360595

Kiely, R. 2013. Sociology and Development: The Impasse and Beyond. London and New York: Routledge Taylor and Francis Group.

Knöbl, W. 2003. Theories that Won't Pass Away: The Never-ending Story. In Delanty, G. \& E.F. Isin (eds.). Handbook of Historical Sociology. UK: Sage. https://doi.org/10.4135/9781848608238.n8

Lutcovich, J.M. 1996. Sociology at a Crossroads: The Challenges of the New Millennium. Journal of Applied Sociology 13,1: 12 - 30.

Meredith, M. 2011. The State of Africa: A History of the Continent since Independence. UK: CPI Group Ltd.

Olutayo A.O. \& A.O. Omobowale. 2007. Capitalism, Globalisation and Underdevelopment Process in Africa: History in Perpetuity. African Development, XXXII,2: 97 - 112.

Olutayo, A.O. 2002. The Concept of Mode of Production in the Analysis of Development. In Isiugo-Abanihe, U.C., A.N. Isamah \& J.O. Adesina (eds.): Currents and Perspectives in Sociology. Nigeria: Malthouse Press Limited.

Omobowale, A.O. \& O. Akanle 2017. Asuwada Epistemology and Globalised Sociology: Challenges of the South. Sociology. 51,1: $43-59$.

https://doi.org/10.1177/0038038516656994

Organisation for Economic Co-operation and Development (OECD) 2008.

Globalisation and Emerging Economies: Brazil, Russia, India, Indonesia,

China and South Africa (BRIICS). www.oecd.org/publishing/corrigenda

Phatlane, I.A. 2016. A Discussion on the Nature and Uses of Sociological 
Theory. Pretoria: University of South Africa.

Ritzer, G. \& J. Stepnisky. 2014. Sociological Theory. $9^{\text {th }}$ Edition. Singapore: Mc Graw-Hill Education.

Rodney, W. 2005. How Europe Underdeveloped Africa. Pretoria: Panaf Publishing Inc.

Rotimi, W. 2009. The Development of Sociology as a Field of Discipline in

Nigeria. In Ogunbameru, O.A. (eds.): Sociology: A Contemporary

Science of Human Interaction in Society. Ibadan: Dop Publications.

Saith, A. 2007. From Universal Values to MDGs: Lost in Transition, Development and Change, 37,6: 1167 - 1199.

https://doi.org/10.1111/j.1467-7660.2006.00518.x

Sitas A. 2006. The African Renaissance Challenge and Sociological

Reclamations in the South. Current Sociology 543: 357 - 380.

https://doi.org/10.1177/0011392106063186

Sitas A. 2011. Response to the Critical Comments. Current Sociology 59,5:

610 - 615. https://doi.org/10.1177/0011392111408672

Sztompka P. 2011. Another Sociological Utopia. Contemporary Sociology 40,4: 388 - 396. https://doi.org/10.1177/0094306111412512

Udefi A. 2014. The Rationale for an African Epistemology: A Critical

Examination of the Igbo Views on Knowledge, Belief, and Justification.

Canadian Social Science 10,3: 108 - 117.

United Nations Department of Economic and Social Affairs.

United Nations Development Programme (UNDP) 2014. 2014 Human

Development Report. http://www.undp.org/content

United Nations Population Information Network (UN POPIN). n.d. Population and Development in Africa, OAU and ECA.

Welz, F. 2009. 100 Years of Indian sociology: From Social Anthropology to Decentring Global Sociology. International Sociology 24,5: 635 - 655. https://doi.org/10.1177/0268580909339270 
Department of Sociology Faculty of The Social Sciences University of Ibadan Nigeria yakanle@yahoo.com olayinkaakanle@gmail.com

o.akanle@ui.edu.ng

Gbenga Adejare Department of Sociology Faculty of the Social Sciences University of Ibadan Nigeria Jare2k@yahoo.com liftedjare@gmail.com 